Terbit online pada laman web jurnal: http://journal.isas.or.id/index.php/JASENS

\begin{tabular}{c} 
JOURNAL OF APPLIED SMART ELECTRICAL \\
NETWORK AND SYSTEMS (JASENS) \\
\hline ISAS
\end{tabular}

\title{
Implementasi Kontrol Proportional - Integral Pada Konverter Bidirectional Untuk Sistem Pengisian Baterai Turbin Angin
}

\author{
Hamlah Nadela Ilif B.J ${ }^{1}$, Herman Hariyadi ${ }^{2}$ \\ ${ }^{1,2}$ Teknik Elektronika, Teknik Elektro, Politeknik Negeri Malang \\ 1nadelahamlah8@gmail.com*
}

\begin{abstract}
The level of demand for electrical energy in Indonesia is currently getting higher and will continue with the increase in population, so that it is required to conduct research in the field of renewable energy. To be able to support renewable energy research, a switching circuit is needed for the battery charging system. The switching circuit used is aKonverter bidirectional circuit controlled by an Arduino Uno microcontroller based on PI (Proportional-Integral) control. PI control functions to regulate the voltage so that it has a stable output voltage value. From the research results of theKonverter bidirectional circuit, using trial and error control constants $\mathrm{Kp}: 2,6$ and $\mathrm{Ki}: 5,6$, it was found that the battery charging time was obtained with an initial voltage of 22.9 Volt to 24 Volt battery without using PI control, which was 6 hours 57 minutes, whereas if using the PI control with Kp: 2,6 and Ki: 5,6 with the initial battery voltage of 22.9 Volt to 24 Volt, the battery charging becomes faster, which is 2 hours 45 minutes.
\end{abstract}

Keywords: Control PI,Konverter bidirectional, Microcontroller, Battery Charging System.

\begin{abstract}
Abstrak
Tingkat kebutuhan energi listrik di Indonesia saat ini semakin tinggi dan akan terus meningkat dengan bertambahnya jumlah populasi, sehingga dituntut untuk melakukan penelitian di bidang renewable energy. Untuk dapat mendukung penelitian renewable energy dibutuhkan rangkaian switching untuk sistem pengisian baterai. Rangkaian switching yang digunakan yaitu rangkaianKonverter bidirectional yang dikontrol oleh mikrokontroler Arduino Uno berbasis kontrol PI (Proportional-Integral). Kontrol PI berfungsi untuk mengatur tegangan agar memiliki nilai tegangan output yang stabil. Dari hasil penelitian rangkaianKonverter bidirectional, dengan menggunakan cara trial dan error konstantan kendali yang didapat adalah Kp: 2,6 dan Ki: 5,6, didapatkan waktu pengisian baterai dengan tegangan awal baterai 22,9 Volt hingga 24 Volt tanpa menggunakan kontrol PI yaitu 6 jam 57 menit, sedangkan jika menggunakan kontrol PI dengan $\mathrm{Kp}: 2,6$ dan $\mathrm{Ki}: 5,6$ dengan tegangan awal baterai 22,9 Volt hingga 24 Volt maka pengisian baterai menjadi lebih cepat yaitu 2 jam 45 menit.
\end{abstract}

Kata kunci: Kontrol PI, Konverter Bidirectional, Mikrokontroler, Sistem Pengisian Baterai.

Diterima Redaksi : 24-05-2021 | Selesai Revisi : 21-06-2021 | Diterbitkan Online : 30-06-2021

\section{Pendahuluan}

Tingkat kebutuhan energi listrik di Indonesia saat ini semakin tinggi dan akan terus bertambah dengan perkembangan jumlah populasinya[1]. Peningkatan kebutuhan tersebut akan berpengaruh pada konsumsi energi fosil sebagai bahan utama dalam menghasilkan energi listrik di Indonesia[9]. Sedangkan jumlah energi fosil di Indonesia sudah semakin berkurang akibat penggunaan secara terus menerus serta energi fosil merupakan energi yang tidak dapat diperbaharui (unrenewable resources)[2]. Maka dari itu diperlukan energi alternatif yang dapat diperbaharui dan tidak menyebabkan polusi seperti energi fosil[3].
Pada Era ini, penelitian dalam bidang renewable energy sudah banyak dilakukan, Di Indonesia sendiri mulai mengembangkan energi angin sebagai sumber energi listrik[10]. Namun, terdapat beberapa kendala dalam pengembangannya, salah satunya adalah kondisi angin di Indonesia yang tidak stabil. Dalam hal ini dibutuhkan sebuah rangkaian elektronika daya berupa konverter DC-DC untuk menyesuaikan tegangan keluaran. Konverter yang digunakan ialahKonverter bidirectional atau konverter DC-DC dua arah[7]. Dalam pemanfaatan rangkaianKonverter bidirectional, maka diperlukan switching otomatis menggunakan mikrokontroler[8]. Dimana sebagai pembangkit sinyal Pulse Width Modulation (PWM) serta pengolah error dengan set point tegangan dan arus[5]. Beberapa metode telah 
dikembangkan untuk dapat mengisi daya pada baterai tegangan pada prototype sistem turbin angin yang secara maksimal dengan menggunakan kemudian masuk ke ADC mikrokontroler.

metodeKonverter bidirectional berbasis Kontrol PI [11] sebagai pengatur daya pada turbin angin Permanent Magnet Synchronous Generator (PMSG) yang dapat bekerja dalam dua mode yaitu mode pengisian dan mode pengosongan, sehingga tegangan keluaran stabil [6]. Penggunaan kontrol PI dapat menghasilkan nilai output yang stabil sesuai dengan set point yang telah ditentukan [4].

\section{Metode Penelitian}

\subsection{Diagram Blok}

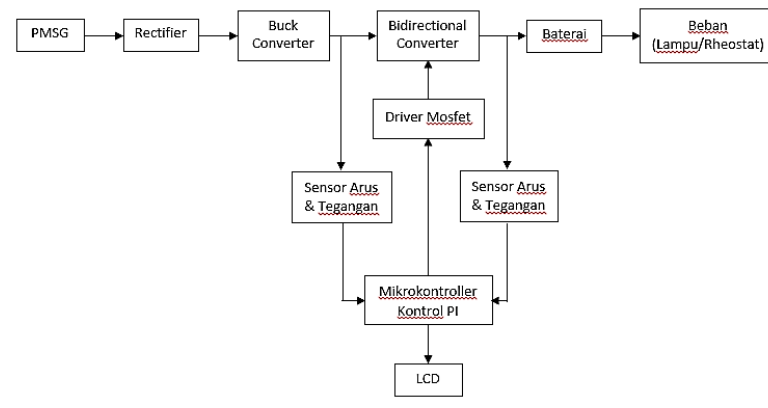

Gambar 1. Diagram Blok

Gambar 1 merupakan diagram blok, prinsip kerja dariKonverter bidirectional yaitu untuk mengatur proses charging dan discharging baterai yang bersumber dari generator. RangkaianKonverter bidirectional menggunakan input PWM dengan tujuan untuk mengatur duty cycle sehingga mendapatkan hasil yang maksimal dalam proses pengisian baterai. Untuk dapat menentukan nilai PWM yang akan digunakan, maka diperlukan sensor arus dan tegangan sebagai feedback ke mikrokontroler. Selama proses charging maupun discharging, sensor arus dan tegangan akan terus bekerja untuk memonitoring input dan output rangkaianKonverter bidirectional. Arduino Uno digunakan untuk membaca output dari sensor arus dan sensor tegangan yang direpresentasikan dengan duty cycle untuk kontrolerKonverter bidirectional melalui Penggerak. Penggerak berfungsi untuk menyesuaikan tegangan output dari mikrokontroler menujuKonverter bidirectional. Input dari sensor arus dan sensor tegangan akan diproses oleh Arduino Uno menggunakan metode Proportional Integral (PI) yang menghasilkan output tegangan yang stabil.

\subsection{Perancangan Sensor Tegangan}

Gambar 2 menunjukkan perancangan sensor tegangan, dalam pembacaan tegangan output generator diperlukan sebuah sensor yang dapat menurunkan tegangan menjadi tegangan yang dibutuhkan oleh ADC mikrokontroler, namun tetap dapat mewakili nilai tegangan asli. Maka digunakanlah prinsip dasar rangkaian listrik voltage divider. untuk menurunkan

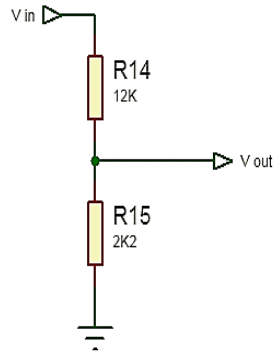

Gambar 2. Rangkaian Sensor Tegangan

Untuk mengetahui besaran komponen yang digunakan R14 dan R15 pada rangkaian sensor tegangan maka dapat menggunakan persamaan yaitu :

Perhitungan Arus Maksimal Pada Beban Resistor

$I_{\text {max }}=\frac{P}{V \max }$
$I_{\text {max }}=\frac{0,25}{30}$
$I_{\text {max }}=8 \mathrm{~mA}$

Perhitungan Nilai Resistansi Total Kedua Resistor

Rtotal $_{\min }=\frac{V \max }{I \max }$

Rtotal $_{\text {min }}=\frac{30}{0,008}$

Rtotal $_{\text {min }}=3,7 \mathrm{k} \Omega$

Perhitungan Nilai Resistansi R1 dan R2

Vout $=\frac{R 2}{R 2+R 1} \times$ Vin

$5=\frac{R 2}{R 2+R 1} \times 30$

$5 R 1+5 R 2=30 R 2$

Jika $R 1=12 k$,

$R 2=(5 \times 12 k)$

\subsection{Perancangan Modul Sensor Arus}

Gambar 3 menunjukkan perancangan sensor arus, fungsi dari sensor arus ACS712 adalah untuk mendeteksi besarnya arus yang mengalir dan mendeteksi besarnya arus pada beban. Modul sensor arus ACS712 dapat mendeteksi arus hingga $5 \mathrm{~A}$ dan sinyal arus ini dapat dibaca melalui IO port Arduino. Sensor ACS712 5A membutuhkan tegangan supply $5 \mathrm{v}$ untuk bekerja.

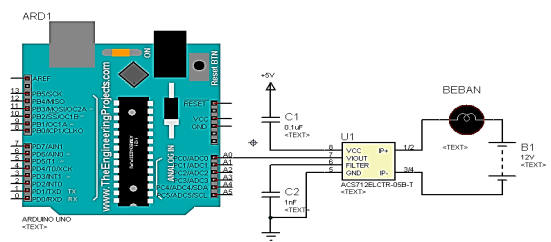

Gambar 3. Rangkaian Modul Sensor Arus 


\subsection{Perancangan Penggerak Mosfet}

Gambar 4 menunjukkan perancangan penggerak mosfet, penggerak mosfet berfungsi untuk mengendalikan kinerjaKonverter bidirectional yang input-nya berupa sinyal PWM. Sinyal PWM tersebut dikontrol melalui Arduino dengan pengendalian nilai duty cycle yang dihasilkan oleh kontrol PI.

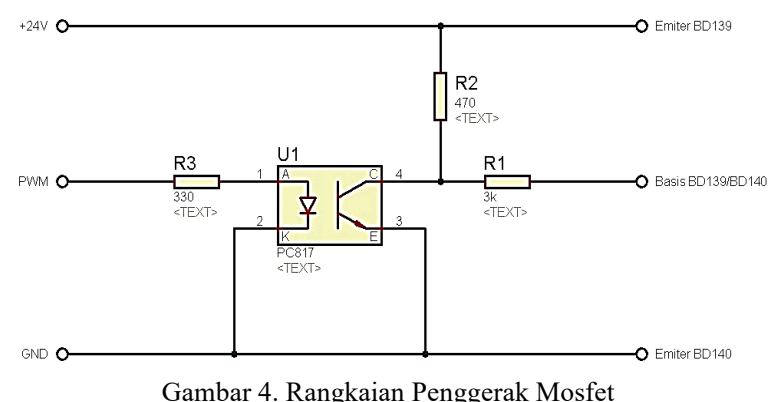

Untuk mengetahui besaran komponen yang digunakan $\mathrm{R} 1, \mathrm{R} 2$ dan R3 pada rangkaian penggerak mosfet maka dapat menggunakan persamaan yaitu :

Perhitungan Mencari Nilai Hambatan R1

$R 1=\frac{V c c-V c e}{I c}$
$R 1=\frac{5-0,7 \text { volt }}{1,5 \mathrm{~A}}$
$R 1=2.866 \Omega$

Pada rangkaianKonverter bidirectional menggunakan resistor $3.0 \mathrm{~K}$ Ohm karena terdapat dipasaran.

Perhitungan Mencari Nilai Hambatan R2

$$
\begin{aligned}
R 2 & =\frac{V c c-V I H}{I H} \\
& =\frac{24-4,5}{0,5} \\
& =39 \Omega
\end{aligned}
$$

Pada rangkaianKonverter bidirectional menggunakan resistor $470 \mathrm{Ohm}$ karena terdapat dipasaran.

Perhitungan Mencari Nilai Hambatan R3

$$
\begin{aligned}
R 3 & =\frac{V o H-V f}{I f} \\
& =\frac{4.8-1.2}{0.02} \\
& =180 \Omega
\end{aligned}
$$

Pada rangkaianKonverter bidirectional menggunakan resistor $330 \mathrm{Ohm}$ karena terdapat dipasaran.

\subsection{Perancangan Konverter bidirectional}

Bidirectional converter memiliki fungsi sebagai nilai maksimum sebesar $956 \mu \mathrm{H}$, maka inductor yang regulator daya pada saat proses charging dan digunakan pada rangkaian sebesar $900 \mu \mathrm{H}$. discharging baterai.Konverter bidirectional digunakan pada saat tegangan output dari prototype turbin angin Perhitungan Nilai Minimal dan Maksimal Kapasitor lebih dari $24 \mathrm{~V}$ maka rangkaian akan bekerja sebagai mode charge. Pada saat tegangan output dari prototipe

turbin angin kurang dari $24 \mathrm{~V}$ maka rangkaian akan bekerja sebagai mode discharge sehingga baterai tidak cepat rusak akibat terus-menerus di-charger.

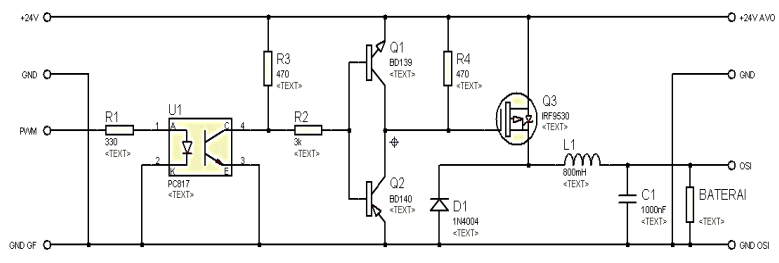

Gambar 5. Rangkaian Konverter bidirectional

Untuk dapat mengetahui besaran komponen yang digunakan seperti tahanan pull up mosfet, duty cycle, induktor dan kapasitor maka dapat menggunakan persamaan yaitu :

Perhitungan Mencari Nilai Hambatan R4

$$
\begin{aligned}
R 4 & =\frac{V c c-V c e(s a t)}{I c} \\
& =\frac{24-0.5}{1.5} \\
& =16 \Omega
\end{aligned}
$$

Pada rangkaianKonverter bidirectional menggunakan resistor $470 \mathrm{Ohm}$ karena terdapat dipasaran.

Perhitungan Nilai Duty Cycle Minimal dan Maksimal

$$
\begin{aligned}
\text { Dmax } & =\frac{\text { Vout }}{\text { Vout-Vin }(\max )} \\
& =\frac{-24}{(-24)-30} \\
& =0,40 \\
\text { Dmin } & =\frac{\text { Vout }}{\text { Vout }- \text { Vin }(\max )} \\
& =\frac{-24}{(-24)-26} \\
& =0,48
\end{aligned}
$$

Perhitungan Nilai Minimal dan Maksimal Induktor

$$
\begin{aligned}
L \text { min } & =\frac{(1-D \min ) R}{2 F s} \\
& =\frac{(1-0,48) 10}{2 \times 31.372,55} \\
& =0,00008287 \\
& =828 \mu \mathrm{H} \\
L \max & =\frac{(1-D \min ) R}{2 F s} \\
& =\frac{(1-0,40) 10}{2 \times 31.372,55} \\
& =0,00009562 \\
& =956 \mu \mathrm{H}
\end{aligned}
$$

Didapat nilai minimum induktor sebesar $828 \mu \mathrm{H}$ dan Journal of Applied Smart Electrical Network and Systems (JASENS) 


$$
\begin{aligned}
C \min & =\frac{V o(1-D \max )}{8 \times 900 \mu H \times 0,3\left(31,5 \times 10^{3}\right) 2} \\
& =\frac{24(1-0,48)}{8 \times 900 \mu H \times 0,3\left(31,5 \times 10^{3}\right) 2} \\
& =0,0000066636 \\
& =6,6 \mu F \\
C \max & =\frac{V o(1-D \max )}{8 \times 900 \mu H \times 0,3\left(31,5 \times 10^{3}\right) 2} \\
& =\frac{24(1-0,40)}{8 \times 900 \mu H \times 0,3\left(31,5 \times 10^{3}\right) 2} \\
& =0,000006718 \\
& =6,718 \mu F
\end{aligned}
$$

Didapat nilai minimum kapasitor sebesar $6.6 \mu F$ dan nilai maksimum kapasitor sebesar $6.718 \mu F$. Maka kapasitor yang digunakan $1000 \mu F$ sesuai dengan yang ada di pasaran.

\subsection{Perancangan Kontrol PI}

Gambar 6 menunjukkan diagram blok kontrol PI, perancangan dilakukan dengan mengatur duty cycle pada penggerak mosfetKonverter bidirectional dengan nilai maksimal sebesar $95 \%$ dan tegangan masukan sebesar $24 \mathrm{~V}$ untuk mendapatkan respon lalu respon tersebut sebagai parameter penentuan nilai $\mathrm{Kp}$ dan $\mathrm{Ki}$.

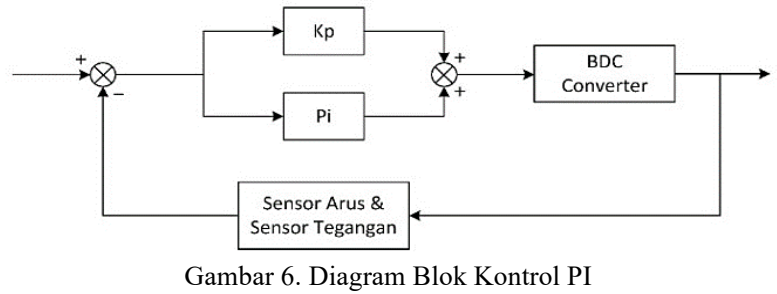

\section{Hasil dan Pembahasan}

\subsection{Pengujian Sensor Tegangan}

\begin{tabular}{|c|c|c|c|c|}
\hline $\begin{array}{c}\text { Vin } \\
\text { (Volt) }\end{array}$ & $\begin{array}{l}\text { Vout } \\
\text { Praktek } \\
\text { (Volt) }\end{array}$ & $\begin{array}{l}\text { Vout } \\
\text { Teori } \\
\text { (Volt) }\end{array}$ & $\begin{array}{c}\text { Error } \\
\text { Praktek } \\
(\%)\end{array}$ & $\begin{array}{c}\text { Error } \\
\text { Teori } \\
(\%)\end{array}$ \\
\hline 4 & 0,6 & 0,62 & $0,02 \%$ & $3,3 \%$ \\
\hline 8 & 1,21 & 1,23 & $0,02 \%$ & $1,65 \%$ \\
\hline 12 & 1,82 & 1,84 & $0,02 \%$ & $1,09 \%$ \\
\hline 16 & 2,46 & 2,46 & $0 \%$ & $0 \%$ \\
\hline 20 & 3.06 & 3,08 & $0,02 \%$ & $0,65 \%$ \\
\hline 24 & 3,63 & 3,7 & $0,07 \%$ & $1,92 \%$ \\
\hline \multicolumn{3}{|c|}{ Rata - rata } & $0,02 \%$ & $1,23 \%$ \\
\hline
\end{tabular}

Tujuan pengujian sensor tegangan untuk mengetahui nilai Vout maksimum yang dihasilkan sebesar $5 \mathrm{~V}$, karena ADC mikrokontroler hanya dapat mengolah nilai tegangan maksimum sebesar $5 \mathrm{~V}$ serta untuk mengetahui perbandingan error antara pengukuran dengan perhitungan seperti pada tabel 1 .

Tabel 1. Tabel Pengujian Sensor Tegangan

Berdasarkan pengujian sensor tegangan, pengujian sensor tegangan dengan praktek didapatkan nilai rata - Pengujian rangkaian Konverter bidirectional rata error $0,02 \%$ sedangkan pada pengujian sensor menggunakan beban baterai 24 Volt, dimana output tegangan teori didapatkan nilai rata - rata error $1,23 \%$. tegangan dariKonverter bidirectional yang diinginkan konstan sesuai dengan input tegangan. Nilai Kp dan nilai

\subsection{Pengujian Sensor Arus}

Pengujian sensor arus bertujuan untuk mengukur arus pada sistem charging baterai serta untuk mengetahui perbandingan error antara pengukuran dengan perhitungan seperti pada tabel 2 .

Tabel 2.Tabel Pengujian Sensor Arus

\begin{tabular}{|c|c|c|c|}
\hline $\begin{array}{c}\text { Iout } \\
\text { Praktek } \\
(\mathrm{A})\end{array}$ & $\begin{array}{c}\text { Iout } \\
\text { Teori } \\
(\mathrm{A})\end{array}$ & $\begin{array}{c}\text { Error } \\
\text { Praktek } \\
(\%)\end{array}$ & $\begin{array}{c}\text { Error } \\
\text { Teori } \\
(\%)\end{array}$ \\
\hline 0.1 & 0.1 & 0.00 & $0.00 \%$ \\
\hline 0.2 & 0.2 & 0.00 & $0.00 \%$ \\
\hline 0.3 & 0.32 & 0.02 & $3.30 \%$ \\
\hline 0.4 & 0.42 & 0.02 & $5.00 \%$ \\
\hline 0.5 & 0.53 & 0.03 & $6.00 \%$ \\
\hline 0.6 & 0.61 & 0.01 & $1.66 \%$ \\
\hline 0.7 & 0.71 & 0.01 & $1.42 \%$ \\
\hline 0.8 & 0.81 & 0.01 & $1.25 \%$ \\
\hline Rata - rata & $0.01 \%$ & $2,32 \%$ \\
\hline
\end{tabular}

Berdasarkan pengujian sensor arus, pengujian sensor arus dengan praktek didapatkan nilai rata - rata error $0,01 \%$ sedangkan pada pengujian sensor tegangan teori didapatkan nilai rata - rata error $2,32 \%$.

\subsection{Pengujian PWMKonverter bidirectional Dengan} Kontrol PI

Pengujian sinyal PWM pada rangkaianKonverter bidirectional dengan kontrol PI dilakukan dengan cara mengganti lebar duty cycle dari $1-90 \%$ dengan input tetap yaitu 26 Volt, lalu amati tegangan keluaran rangkaian Bidirectioal Konverter menggunakan multimeter seperti pada tabel 3.

Tabel 3.Tabel Pengujian PWM Bidirectional Dengan Kontrol PI

\begin{tabular}{|c|c|c|c|c|}
\hline $\begin{array}{c}\text { Frekuensi } \\
(\mathrm{Hz})\end{array}$ & $\begin{array}{c}\text { ADC } \\
(\text { Arduino })\end{array}$ & $\begin{array}{c}\text { PWM } \\
(\%)\end{array}$ & $\begin{array}{c}\text { Vin } \\
(\mathrm{V})\end{array}$ & $\begin{array}{c}\text { Vout } \\
(\mathrm{V})\end{array}$ \\
\hline 32000 & 25,5 & $10 \%$ & 26 & 6,1 \\
\hline 32000 & 51 & $20 \%$ & 26 & 9,3 \\
\hline 32000 & 76,5 & $30 \%$ & 26 & 11,9 \\
\hline 32000 & 102 & $40 \%$ & 26 & 14,6 \\
\hline 32000 & 127,5 & $50 \%$ & 26 & 17,2 \\
\hline 32000 & 153 & $60 \%$ & 26 & 22 \\
\hline 32000 & 178,5 & $70 \%$ & 26 & 23,3 \\
\hline 32000 & 204 & $80 \%$ & 26 & 24,6 \\
\hline 32000 & 229,5 & $90 \%$ & 26 & 26,7 \\
\hline
\end{tabular}

Pada pengujian Sinyal PWM rangkaian Bidirectional didapatkan jika duty cycle bertambah besar maka resolusi dan tegangan output rangkaianKonverter bidirectional akan bertambah besar, sedangkan jika duty cycle bertambah kecil maka resolusi dan tegangan output rangkaianKonverter bidirectional akan bertambah kecil.

\subsection{Pengujian Konverter bidirectional Dengan Kontrol} PI

Journal of Applied Smart Electrical Network and Systems (JASENS) 
Ki ditentukan diawal dengan nilai Kp: 2,6 dan Ki: 5.6. Penentuan nilai $\mathrm{Kp}$ dan nilai $\mathrm{Ki}$ berdasarkan trial and error seperti pada tabel 4.

Tabel 4.Tabel Pengujian Bidirectional Dengan Kontrol PI

\begin{tabular}{|c|c|c|}
\hline $\begin{array}{c}\text { Vin } \\
(\mathrm{V})\end{array}$ & Vref (set point) & $\begin{array}{c}\text { Output } \\
(\mathrm{V})\end{array}$ \\
\hline 25.6 & 22 & 20.9 \\
\hline 25.5 & 22 & 21 \\
\hline 25.3 & 22 & 21.2 \\
\hline 25.6 & 22 & 21.7 \\
\hline 25.4 & 22 & 21.6 \\
\hline 25.6 & 22 & 21.9 \\
\hline
\end{tabular}

Berdasarkan pengujian rangkaianKonverter bidirectional dengan Vref tetap yaitu 22 Volt dan tegangan input 25 Volt sehingga didapatkan tegangan output cenderung berubah-ubah

\subsection{Pengujian Charging Baterai Tanpa Kontrol PI}

Pengujian dilakukan tanpa menggunakan kontrol PI dengan menggunakan keluaran dari rectifier yang tidak stabil. pengujian charging baterai tanpa kontrol PI dilakukan dengan cara menghubungkan rangkaianKonverter bidirectional ke turbin angin sebagai tegangan input lalu untuk dapat memonitor tegangan input dan output rangkaianKonverter bidirectional maka digunakanlah LCD, serta untuk mengetahui lama pengisian baterai menggunakan timer seperti pada tabel 5 .

Tabel 5.Tabel Pengujian Charging Baterai Tanpa Kontrol PI

\begin{tabular}{|c|c|c|c|}
\hline $\begin{array}{c}\text { Tegangan } \\
\text { Masukan (V) }\end{array}$ & $\begin{array}{c}\text { Tegangan } \\
\text { Awal } \\
\text { Baterai } \\
(\mathrm{V})\end{array}$ & $\begin{array}{c}\text { Tegangan } \\
\text { Akhir } \\
\text { Baterai } \\
(\mathrm{V})\end{array}$ & $\begin{array}{c}\text { Waktu } \\
\text { Pengisian (Jam) }\end{array}$ \\
\hline $25.50-29.00$ & 22.9 & 24.00 & 6 jam 57 menit \\
\hline $25.50-29.00$ & 20.7 & 24.00 & 20 jam 51 menit \\
\hline $25.50-29.00$ & 18.5 & 24.00 & 34 jam 45 menit \\
\hline
\end{tabular}

Berdasarkan pengujian charging baterai tanpa kontrol PI dapat disimpulkan bahwa jika tanpa kontrol PI maka tegangan output rangkaianKonverter bidirectional cenderung tidak terkontrol serta lebih lambat saat mencharger baterai.

\subsection{Pengujian Charging Baterai Dengan Kontrol PI}

Pengujian rangkaianKonverter bidirectional dengan menggunakan Kontrol PI dengan meggunakan output tegangan dari rectifier yang stabil, Kemudian mengatur nilai duty cycle, untuk dapat memaksimalkan pengisian baterai seperti pada tabel 6 .

Tabel 6.Tabel Pengujian Charging Baterai Dengan Kontrol PI

\begin{tabular}{|c|c|c|c|}
\hline $\begin{array}{c}\text { Tegangan } \\
\text { Masukan (V) }\end{array}$ & $\begin{array}{c}\text { Tegangan } \\
\text { Awal } \\
\text { Baterai } \\
(\mathrm{V})\end{array}$ & $\begin{array}{c}\text { Tegangan } \\
\text { Akhir } \\
\text { Baterai } \\
(\mathrm{V})\end{array}$ & $\begin{array}{c}\text { Waktu Pengisian } \\
(\text { Jam })\end{array}$ \\
\hline $25.50-29.00$ & 22.9 & 24.00 & 2 jam 45 menit \\
\hline $25.50-29.00$ & 20.7 & 24.00 & 8 jam 15 menit \\
\hline
\end{tabular}

\begin{tabular}{|l|l|l|l|}
\hline $25.50-29.00$ & 18.5 & 24.00 & 14 jam 45 menit \\
\hline
\end{tabular}

Berdasarkan pengujian charging baterai dengan menggunakan kontrol PI dapat disimpulkan bahwa jika dengan kontrol PI maka tegangan ouput rangkaianKonverter bidirectional cenderung terkontrol serta lebih cepat meng-charger baterai.

\section{Kesimpulan}

Dari hasil pengujian yang telah dilakukan dapat diambil kesimpulan, RangkaianKonverter bidirectional menggunakan optocoupler sebagai penggerak mosfet, Transistor PNP BD139 yang terhubung ke Mosfet IRF9530 sebagai switching. Untuk mengaktifkan switching mosfet diperlukan frekuensi $32 \mathrm{kHz}$ yang dikontrol oleh Arduino Uno dan dikirim oleh penggerak mosfet. Sehingga dapat menstabilkan tegangan sesuai persamaan Vout $=$ Vin $x$ D pada range tegangan input 15 -30 Volt dengan duty cyle $1-95 \%$. Kontrol PI dengan nilai $\mathrm{Kp}=2.6, \mathrm{Ki}=5.6$ digunakan untuk mengontrol teganganKonverter bidirectional agar sesuai dengan nilai setpoint sebesar 24 Volt dan respon setting time menjadi lebih cepat serta tidak mengalami osilasi yang berlebihan. Pada saat proses pengisian baterai diperlukan tegangan lebih dari 27 Volt untuk menjaga agar baterai tidak rusak.

Rancangan yang dibuat ini masih perlu adanya perbaikan agar bekerja optimal. Ada beberapa hal yang direkomendasikan untuk pengembangan lebih lanjut yaitu, menggunakan kontrol PID untuk sistem pengisian baterai yang lebih maksimal karena dengan menggunakan kontrol PID dapat memberikan respon yang lebih baik. Selain itu, menyempurnakan rangkaianKonverter bidirectional, agar tegangan output yang dihasilkan bias lebih stabil.

\section{Daftar Rujukan}

[1] Rudiyanto, B., 2016. Aplikasi Kontrol PI (Proportional Integral) pada Katup Ekspansi Mesin Pendingin, Jurnal Roya Teknik Pertanian, 9 (2), pp.89-105.

2] Anto, B., 2014. Portable Battery Charger Berbasis Sel Surya, Jurnal Rekayasa Elektrika, 11 (1), pp.19-24.

3] Hermansyah., 2015. Simulasi Double Buck Boost Konverter DCDC Bidirectional Menggunakan PID Controller, Prosiding SENTIA, 7 (1), pp.1-6.

[4] Linggasari, Y.R., 2016. Rancang BangunKonverter bidirectional Menggunakan Kontrol Proportional Integral Untuk Sistem Pengereman Regeneratif, e-Proceeding of Engineering, 3 (1), pp.84-90.

5] Pratiwi, A.S., 2020. Desain dan Simulasi Bidirectional DC-DC Konverter Untuk Penyimpanan Energi pada Sistem Fotovoltaik, Jurnal Nasional Teknik Elektro dan Teknologi Informasi, 9 (3), pp.305-310.

[6] Lucky, P., 2019. Perancangan dan Implementasi DCDCKonverter bidirectional Dengan Sumber Energi Listrik Dari Panel Surya dan Baterai Untuk Pemenuhan Kebutuhan Daya Listrik Beban, Jurnal Teknologi Terpadu, 7 (2), pp.111-118.

[7] Sulistomo, P., 2018. Implementasi Pengendalian Sistem Pengisian/Pengosongan Baterai Pada Sistem Photovoltaic StandAlone MenggunakanKonverter bidirectional Dengan Metode Proportional-Integral Berbasis Mikrokontroler DSPIC30F4011", TRANSIENT, 7 (4), pp.832-837.

[8] Prasetiyo, H.C., 2018. Optimalisasi Daya Pembangkit Listrik Tenaga Angin Menggunakan Maximum Power Point Tracker

Journal of Applied Smart Electrical Network and Systems (JASENS) 
(MPPT) Dengan Metode Perturb And Observe (P\&O), TRANSIENT, 7 (2), pp.77-83.

[9] Hafiz., 2017. Kontrol Proportional-Derivatif Pada Sistem Dinamik Pesawat Terbang Tipe Airbus A380-800, Jurnal Ilmiah Matematika, 3 (6), pp.43-51.

[10] Rahayu, N., 2020. Desain dan Implementasi Bidirectional DC-DC Konverter Untuk Penerangan Darurat, Jurnal ECOTIPE, 7 (2), pp.108-116.

[11] Sheren, D., 2020. Rancang Bangun Buck Boost Konverter Menggunakan Kendali PID, Jurnal Teknik Elektro dan Vokasional, 6 (2), pp.258-272. 